\title{
Sustainable bus transports through less detailed contracts
}

\author{
Helene Lidestam ${ }^{1, *}$ \\ ${ }^{1}$ Department of Management and Engineering, Linköping, Sweden \\ * Corresponding author. Tel: +46 13282433, Fax: +46 13281101, E-mail:helene.lidestam@liu.se
}

\begin{abstract}
The purpose of this paper is to investigate both environmental effects and cost effects of using less specified contracts regarding bus sizes in public bus transports. The process of choosing the best bid in the public procurement of bus transports is easier if the demands of the qualifications are well specified and detailed. On the other hand, detailed contracts can force the entrepreneurs to use less environmentally friendly and uneconomical alternatives. The process of choosing the best bid in the public procurement process will be more complicated when the contracts are less detailed compared to current situations. Indeed, using less detailed contracts leads to decreased emissions and probably costs for all parts involved. A mathematical model with binary variables is developed in order to evaluate the environmental and the economic effects of using less detailed contracts in the public procurement of bus transports and in turn more suitable bus sizes. Computational results with data from a Swedish bus service provider are presented. The results of the model indicate that the emissions decrease considerably by using less detailed contracts. The results of a sub case indicate that the costs could be reduced as well, depending on how efficient the additional buses can be planned.
\end{abstract}

Keywords: Environmental sustainability, Bus transports, Public procurement, Mathematical modeling

\section{Introduction}

Many nations have converted their public transport systems from monopoly transit systems to competitive tendering. One of the first regions to use fully-tendering regime was London in 1985 [1]. An overview of international successful and less successful ways to use competitive tendering as a possibility to decrease the subsidies within the business of public bus transports has been presented [1]. The competitive tendering system has worked satisfactory in most of the European countries. Two exceptions are Italy and France where the transfer to the competitive tendering system has not affected the transports costs at all [2]. However, the costs have a tendency to be low at the first time competitive tendering is used and then instead increase for the second and third time the system is used [1]. This form of tendering often leads to changes of the structure of the actors involved in the process. Going from a market including many small actors, the actors are now few and large [1]. The system for public procurement in Sweden started through a national resolution in 1985, which led to a law coming into effect in 1989 [3]. The process for the regulations for procurement of public bus transport in Sweden is based on EU public-procurement guidelines. The most common form of contracts used in Sweden is gross contracts, where the bus entrepreneur only gets paid for the costs and is not involved in the ticket revenues. The most common way to choose the winning bid is to use so called first-price auction, which is to choose the bid with the lowest price as a winner. By using this combination the final contracts will often be very detailed. An earlier study showed that the $\mathrm{CO}_{2}$-emissions can be reduced considerably by using less specified contracts with respect to bus sizes in the public bus transports [4]. The part of traffic being involved in the public procurement processes has increased drastically since and is now (2010) around 90\%. The process of choosing the best part in the public procurement of bus transports is easier if the demands of the qualifications are well specified and detailed. On the other hand, detailed contracts will lead to limitations and could force the entrepreneurs to use uneconomical, but most of all, less environmentally friendly alternatives. The resulting contracts are indeed very detailed and there is not much inbuilt flexibility regarding for example the bus sizes. Using large buses with many bus seats for transporting few persons is 
expensive, both in economic terms and most important in emission terms The trade organizations within the public bus transports area in Sweden have a common goal to double the public transports to 2020 and this ambition is in line with the aim in EU declaring that the emissions should decrease considerably. The purpose of this research was to study the cost effects of using more environmental-friendly bus traffic. The economic and environmental consequences are two of three essential aspects in sustainability. The third aspect concerns the social area. As increased emissions can lead to diseases, also this aspect is affected negatively when using non environment-friendly solutions. The outline of the paper is as follows. The methodology is presented in Section 2 and in Section 3 the mathematical model for the problem is formulated. Data from a real-life case is studied and presented in Section 4. The computational results are presented in Section 4 and finally, in Section 6, some concluding remarks are viewed.

\section{Methodology}

A mathematical optimization model with binary variables is developed to evaluate the environmental and cost effects of more optimized bus sizes. The mathematical model is carefully described in Section 3. We have used the program, AMPL, for modeling the problem and the commercial program CPLEX, version 10.2.0, is used to solve the model. These programs are suitable when the mathematical models include binary or integer variables. Data needed for the study is collected for one region in Sweden and is provided by a large Swedish bus entrepreneur, called Nobina Bus AB. All distances from one stopping place to the next stopping place on all chosen bus tours have been used as well as different kind of buses and their capacity in terms of number of seats. Finally, the levels of $\mathrm{CO}_{2}$ emissions (kilogram per kilometers) and costs (Swedish crowns per kilometers) for each kinds of bus type are considered. Two opposite scenarios have been tested in order to evaluate the environmental effects of more details in contracts. The scenarios are shortly described below:

Scenario A - This is the basic scenario and it shows the current situation in the chosen region. The contract for bus traffic in the area defines which type of buses those have to be used on which bus tours.

Scenario B- The possibility to use additional buses along the lines is tested. Sometimes a large bus can drive empty from the starting place to the second last stopping place and then it can get a lot of passengers for the last part of the line. No restrictions regarding the choice of bus type. The results in this scenario show the level of $\mathrm{CO}_{2}$-emissions when as small buses as possible, with respect to $\mathrm{CO}_{2}$ emissions, are used. The possibility to use other bus types is also tested.

The economic effects of using more flexible and less detailed contracts in the public procurement process are evaluated in the specific case described in Section 4. This case is a sub case of the general case. In order to get a more lifelike situation, some restrictions are added into the relevant scenarios. They are further described in Subsection 4. The results from the sub case are compared to the current daily planning by the involved bus entrepreneur. The results of the model will give a solution that uses as small bus sizes as possible with respect to the costs.

\section{Mathematical model}

In this section we present the mathematical model for the problem of evaluation of public procurement of bus transports. The model is used in order to find as small buses as possible to use of each part of the bus tours. The model consists of an objective function, binary 
variables, parameters and constraints. We first describe the parameters and the variables. Thereafter the objective function is presented and finally, the constraints are described. The original model is earlier presented [4].

\section{Parameters}

$h_{i}=\mathrm{CO}_{2}$ emissions measured in kilogram per kilometer from bus type $i$.

$a_{j k}=$ the distance from stopping place $k$ to the next stopping place at line $j$.

$e_{j k}=$ the number of people getting on the bus at stopping place $k$ at line $j$.

$r_{j k}=$ the number of people getting off the bus at stopping place $k$ at line $j$.

$P_{i}=$ the capacity for bus type $i$ measured in number of seating places.

\section{Variables}

$\boldsymbol{B}_{\boldsymbol{i j k} \mathbf{k}}= \begin{cases}1, & \text { if bus type } \boldsymbol{i} \text { is used from stopping place } \boldsymbol{k} \text { to the next stopping place on line } \boldsymbol{j} \\ 0, & \text { else. }\end{cases}$ $i=1 . . \mathrm{m}, j=1 . . \mathrm{n}, k=1 . . \mathrm{h}$

\section{Objective function}

$\operatorname{Min} \sum_{i} \sum_{j} \sum_{k} \boldsymbol{a}_{j k} \boldsymbol{h}_{i} \boldsymbol{B}_{i j k}$

\section{Constraints}

$$
\begin{aligned}
& \sum_{i} P_{i} B_{i j k} \geq e_{j 1} \forall j, \forall k: k=1 \\
& \sum_{i} P_{i} B_{i j k}-\sum_{k=1}^{k-1} e_{j k}+\sum_{k=1}^{k} r_{j k} \geq e_{j k} \forall j, \forall k: k \geq 2 \\
& B_{i j k} \geq B_{i j k-1} \forall k \geq 2, \forall i, \forall j \\
& B_{i j k} \in\{0,1\} \text { (4) }
\end{aligned}
$$

The objective function minimizes the $\mathrm{CO}_{2}$-emissions. The distance between all stopping places at the lines is multiplied with the $\mathrm{CO}_{2}$-emissions from the different bus types, respectively. The constraints (1) make sure that the capacity of the used buses is enough that is that all of the people that get on the bus at the starting point have a seat place on the bus. The constraints (2) ensure that all the people getting on the buses at the forthcoming stopping places gets a seat place on the used buses. The fact that one bus has to following the whole line after it has started is described in the constraints (3). The constraints (4) express that all variables are binary, that is they could either be 1 or 0 . Constraints (3) also allow buses to start on a later stopping place along the line, but it has to continue to drive to the end of the line. If there is no possibility to add buses along the line the constraints (3) can instead be described as constraints (5) given below: 


$$
B_{i j k}=B_{i j k-1} \quad \forall k \geq 2, \forall i, \forall j \quad(5)
$$

To evaluate the specific case and to reach the lowest level of included costs, the objective function in the model is modified in the following way:

$\operatorname{Min} \sum_{i} \sum_{j} \sum_{k} \boldsymbol{a}_{j k} \boldsymbol{c}_{i} \boldsymbol{B}_{i j k}$

where $C_{i}=$ costs measured in Swedish crowns per kilometer regarding bus type $i$. The costs refer to variable driving costs. The fixed capital costs, mainly for depreciations, are added afterwards in order to compare different scenarios. The constraints used for the specific case are the same as above (1-4). The model does not consider any limitations of the number of buses that can be used for different lines. The distance between one stopping place at a line and a starting place at another line and the distance to the bus garage is not regarded in the problem. The different times for the lines are counted only as different lines so the time aspect and any possible limitations of the use of different bus types has not been considered as well in the problem.

\section{Case study}

Nobina $\mathrm{AB}$, earlier called Concordia Nordic Bus $\mathrm{AB}$, is the largest bus transport company in the Nordic countries and one of the ten largest in Europe. Nobina AB works for different public authorities in Sweden. The name of the public authority for the region considered in this study is Västtrafik. The general case included 103 different lines. The lines are divided into several sub lines depending on the number of stopping places along the line. For each line there are different variants of the line. The variants differ regarding the included stopping places and their order. Each variant of a line is used several times in a 24 hour. In total it is 2044 tours including 2037 stopping places during a day in the selected area and the number of counted people getting on (and off) the buses is 34 312. Seven types of buses are used by Västtrafik and taken into account in the scenarios. The capacity of the different type of buses is from 23 seats to 56 seats and the levels of $\mathrm{CO}_{2}$-emissions range from $0,83 \mathrm{~kg} / \mathrm{km}$ to 0,99 $\mathrm{kg} / \mathrm{km}$. For each bus type, the related seat capacity and $\mathrm{CO}_{2}$-emissions are given. The $\mathrm{CO}_{2}-$ emissions are defined by kilogram per kilometer. The presented model will minimize the level of $\mathrm{CO}_{2}$-emissions.

The calculations of the emissions are based on road driving with few stops. The most important factor to consider in this paper is the difference in emissions due to the size of the bus type, which in this case is measured in number of seats in each bus type. Therefore the other depending factors, for example type of engine and driving properties are equal in of all the bus types. The considered engine in all of the bus type is a euro3 engine. The newer engine euro5 has fewer emissions but the difference is mostly related to the NOx-emissions and SOx. The figures on $\mathrm{CO}_{2}$-emissions are considered proportionate to fuel-consumption. The fact that a full bus has more $\mathrm{CO}_{2}$-emissions compared to an empty bus has not been considered in the optimization, however, it can be calculated and evaluated after the optimization has been made if needed. In scenario B, two additional bus types are possible to use; one large bus taking 65 passengers with $1,15 \mathrm{~kg} / \mathrm{km}$ of $\mathrm{CO}_{2}$-emissions and one small bus taking only eight passengers with $0,3 \mathrm{~kg} / \mathrm{km}$ of $\mathrm{CO}_{2}$-emissions.

An area of bus traffic is chosen from the general case in order to investigate the economic effects on a given real planning situation. One hundred tours (around $5 \%$ ) of 2044 in total 
are included in the specific case. The total length of these tours is 5750 kilometers to compare to the total length of the general case which is 44790 kilometers. The bus traffic for the specific case is chosen in cooperation with the planning manager at the involved company Nobina AB. One reason for choosing this area and these tours was that the traffic is expected to be heavy and the buses are supposed to be more full compared to an average tour in the area of the general case. The 100 used tours are divided into 14 bus trips. The bus trips describe the day of each bus. The current situation at the chosen region is that 14 large buses (Express buses) are used on the 100 tours. The bus goes from the garage in the morning and back to the garage at the evening. The bus trips can include from five to nine different tours. A typical example of a bus trip is illustrated in Figure 4.1. This bus trip (on the x-axis) includes seven different bus tours (the piles) represented in time order, that is the first tour represents the early morning and the last tour represents the late afternoon or evening for the bus trip. The y-axis shows the number of passengers on each tour. Each bus tour includes a number of lines between the stopping places and the number of passengers in Figure 4.1 refers to the highest number of passengers on the each tour. That means that the situation can be that the bus drives empty most of the distances and drives with many passengers, for example 50, only on one of the included lines. Then the number of passengers, in Figure 4.1 below, will be 50 on that tour. Most of the bus trips look like the one below in that sense that number of passengers on the tours included varies a lot. As mentioned before only type of large buses are used today in this area. The average number of the highest level of passengers is 24 on the 100 included tours.

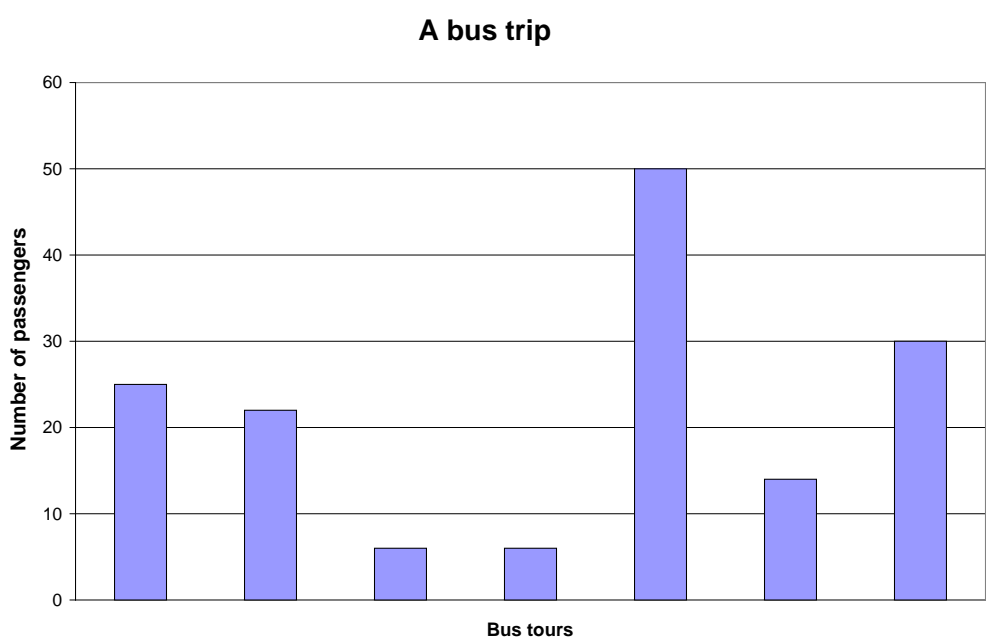

Figure 4.1 Example of a bus trip

Alternatives to use only large Express-buses can be to use as small buses as possible on the fourteen tours. That is further on called using adaptive bus sizes and that will of course also lead to the use of fourteen buses. Another alternative that will be investigated on the specific case is to use another bus type, here called Middle-bus, as a standard bus and then use smaller buses, here called Mini-buses, as additional buses that can be used whenever needed between one or several stopping places. The capacity of the Middle-bus, in terms of seats, is 32 and the capacity of the Mini-bus is 15 . The $\mathrm{CO}_{2}$-emissions from the Middle-bus and the Mini-bus are 0,45 and 0,35 kilogram per kilometers, respectively, compared to the level of 0,96 kilogram per kilometers from the Express-bus. Regarding the alternative of using adaptive bus sizes, the bus type Ordinary is also taken into account. The level of $\mathrm{CO}_{2}$-emissions from that bus type is 0,93 kilogram per kilometers and the number of seats is 46 . The considered variable costs are referred to costs for operating the bus and costs regarding the bus driver. The 
included fixed costs are capital costs, mainly with respect to the depreciations and based on the purchase cost. The levels of the different costs are collected and evaluated by the planning manager for Nobina AB in the area of the specific case.

\section{Results}

The resulted levels of $\mathrm{CO}_{2}$-emissions from the scenarios in the general and the specific case are presented in Table 5.1. The level of $\mathrm{CO}_{2}$-emissions is calculated based on the level of emissions per 24 hours workday. The bus traffic on workdays is on average four times more intense compared to the bus traffic on Saturdays and Sundays. We have estimated the number of workdays in a year to 245 and the official holidays, including Saturdays and bridges days, to 120 . The differences compared to Scenario A are given in percent.

Table 5.1 Comparison of the two cases.

\begin{tabular}{lcrr}
\hline Case & Scenario & $\mathbf{C O}_{2} \mathbf{~ k g} /$ year & Difference \\
\hline General & $\mathrm{A}$ & 11765150 & $0 \%$ \\
\hline General & $\mathrm{B}$ & 7653800 & $-34 \%$ \\
\hline Specific & $\mathrm{A}$ & 1554300 & $0 \%$ \\
\hline Specific & $\mathrm{B}$ & 1183050 & $-24 \%$ \\
\hline
\end{tabular}

The results from the two scenarios, indicate a clear relation between $\mathrm{CO}_{2}$-emissions and contract-flexibility. By letting the number of passengers decide which bus size to use instead of following the contract regulations, the $\mathrm{CO}_{2}$-emissions can be decreased by $34 \%$. The possibility to add buses along the tours create a need for more small buses. A disadvantage by using smaller buses is the fact that more buses have to be used. The buses will in total be used on shorter distances but indeed more buses on a line results of course in more bus drivers. It is a trade-off between the fixed costs of having several bus drivers and the ambition to drive as small buses as possible in order to reduce the $\mathrm{CO}_{2}$-emissions. The fact that the difference between Scenario A and Scenario B in the general case is larger compared to the difference between the same scenarios in the specific case indicates that the chosen area for the specific case is not fully representative for the general case. The results above also tell that there are other areas in the general case that would gain more, with respect to lower $\mathrm{CO}_{2}$-emissions, by using more flexible and less regulated contracts. The solution times regarding the general case are less than 20 minutes and the solution times for the specific case are all very small, below one minute.

The current situation, only use Express-buses, is compared to other alternatives regarding the specific case. The first alternative to investigate was to adaptive bus sizes. To find and use the smallest bus for each trip resulted in seven Express-buses, six Ordinary-buses and one Middle-bus and these changes would lead to $5 \%$ lower $\mathrm{CO}_{2}$-emissions on the same number of active kilometers compare to the current situation. The second alternative investigated was to use another type of base bus, Middle-bus on all trips and then when necessary use additional, Mini-buses, on parts of the tours. By using fourteen Middle-buses and seventeen Mini-buses the $\mathrm{CO}_{2}$-emissions can be reduced by as much as $47 \%$.

The results, however, only present the $\mathrm{CO}_{2}$-emissions from the active driving in the tours. The driving from the bus garage to the first tour in the morning and the driving from the last tour in the evening back to the bus garage are not taken into account. Also the fact that the buses used on one or several sub distances between stopping places on one tour also are used for other sub distances on other tours lead to additional $\mathrm{CO}_{2}$-emissions. These extra $\mathrm{CO}_{2}$ - 
emissions are not been taken into consideration in the above table. The circumstances of using additional buses on the trips lead to a larger number of active kilometers, 6677 compared to 5 750. The plan of where different buses will be used has been showed to the planning manager. He has, from his point of view, estimated the practical need for buses in the current area to be 10 additional Mini-buses. Therefore the calculations regarding costs are made for using 10 additional buses. The results measured in emissions and costs for using different kind of combinations of bus types on the fourteen bus trips are presented in Table 5.2.

Table 5.2 The results regarding $\mathrm{CO}_{2}$-emissions and costs from the specific case.

\begin{tabular}{lccrcc}
\hline Used buses & $\begin{array}{l}\text { Active } \\
\text { kilometers }\end{array}$ & $\mathbf{C O}_{\mathbf{2}} \mathbf{k g} / \mathbf{y e a r}$ & Difference & $\begin{array}{l}\text { Total costs } \\
\text { (SEK/year) }\end{array}$ & Difference \\
\hline 14 Express & 5750 & 1518000 & $0 \%$ & 30449000 & $0 \%$ \\
\hline $\begin{array}{l}7 \text { Express } \\
\text { 6 Ordinary }\end{array}$ & 5750 & 1438000 & $-5 \%$ & 28009000 & $-8 \%$ \\
1 Middle & & & & & \\
\hline $\begin{array}{l}14 \text { Middle } \\
10 \text { Mini }\end{array}$ & 6677 & 800786 & $-47 \%$ & 24997660 & $-18 \%$ \\
\hline
\end{tabular}

The calculations made by the planning manager showed that adding 10 more buses in the current situation will increase the costs by $10 \%$. There is apparently a gap from decreasing the costs by $18 \%$ to increasing the costs by $10 \%$ due to how the additional buses can be scheduled. However, the value of lowering the emissions and in turn improving the environment is hard to measure and compare to the increasing related costs.

\section{Conclusions}

The results of the mathematical model indicate that all parts involved in the public procurement process, the public authority, the entrepreneur and the customers, will gain from more flexible and less detailed contracts. The results from the general case expose notable lower levels of $\mathrm{CO}_{2}$-emissions when the contracts are more flexible and without detailed restrictions. The levels of $\mathrm{CO}_{2}$-emissions decrease by $34 \%$ from the current situation to the most flexible scenario (Scenario B). The results from the specific case indicate that the costs could be reduced as well, depending on how efficient the additional smaller buses can be planned. The results indicate that the emissions can be reduced up to $47 \%$ by using smaller buses in traffic and the costs can in worst case increase by $10 \%$. Anyway, there are possibilities to decrease the costs as well if the operations planning changes. That could be done for example by expanding the planning area for the buses in order to increase the possibility to make use of returns to scale and coordination advantages. Other kinds of entrepreneurs, such as taxicabs, could also be used in addition to the ordinary buses. That will lead to more flexibility. Another base for getting lower cost could be to plan the bus trips in a different way. The occupancy level on the buses in general could probably be higher if the tours for a bus trip have more equal occupancy levels. The number of on and off-going people in the studied bus trips in the specific case varies a lot along the trip. The possibility to use parking places for the buses along the tours in addition to the bus garage could also decrease the bus driving. Directions for future research could therefore include the above suggestions in order to show the possibility to reduce both the $\mathrm{CO}_{2}$-emissions as well as the costs considerably. In order to get a more complete view, other aspects, for example the traveler behavior connected to the level of occupied buses should be further investigated. The results from the optimization model show that detailed rules in the public procurement process lead to increased $\mathrm{CO}_{2}$-emissions and probably higher overall costs, and therefore it would be 
highly motivated by the politicians to evaluate the Swedish system. The research will therefore contribute to the operation management planning in order to achieve the overall aim to reduce $\mathrm{CO}_{2}$-emissions. The actors in the public bus transport business should as well be interested in getting insight in how fewer restrictions in the contracts will affect them.

\section{References}

[1] D.A. Hensher and I.P. Wallis, Competition tendering as a contracting mechanism for subsidising transport - The bus experience, Journal of Transport Econimics and Policy 39, 2005, pp. 295-321.

[2] A. Boitan and C. Cambini, To bid or not to bid, this is the question: the Italien experience in competitive tendering for local bus services, European Transport 33, 2006, pp. 41- 53.

[3] P. Elvingson, Bättre kollektivtrafik, ISBN 915586951 3, $\quad$ Svenska Naturskyddsföreningen, 2005. (in Swedish)

[4] H. Lidestam and M. Abrahamsson, Mathematical modeling for evaluation of public procurement for bus transports in terms of emissions, Management of Environmental Quality 5(3), 2010, pp. 645-658. 